\title{
Ebooks and the distance learner
}

\author{
Claire Grace and Gill Needham
}

The Open University

\section{What we can do for students now}

Emily is in her second year studying psychology with the Open University (OU). She chose to study in this way while working full time as a classroom assistant in a primary school. Her best friend from school, Carole, is a year ahead, attending a campus university as a full-time student. Carole is also studying psychology, and the two friends meet up from time to time to share gossip, compare experience and sometimes help one another with their work. They meet for a coffee one Saturday. Carole is a little late. "I'm so sorry" she says "I've been queuing up in the library, trying to get hold of this book I need from short loan for the weekend - my essay's due in next week." "I get the feeling you weren't successful?" "No I wasn't, and I'm really stuck now - it's only published in print. I might just have to buy a copy - it's paperback, but it’s $£ 25$ I would rather not spend." "Well, that's one problem I don't have” says Emily. "How does that work, exactly?" Carole asks "How do you get hold of library books?". "Well, the books we are expected to read are all there for us online - the only 'real' book I have for the course is the one set book I had to buy at the beginning".

Carole's question and Emily's subsequent explanation is the crux of the question we shall address in this chapter - "Why are ebooks important in

\section{How to cite this book chapter:}

Grace, C. and Needham, G. 2014. Ebooks and the distance learner. In: Woodward, H. (ed.) Ebooks in Education: Realising the Vision. Pp. 15-20. London: Ubiquity Press. DOI: http://dx.doi.org/10.5334/bal.c 
distance education?". For OU students, all of whom study at a distance, their library service is the online library, and ebooks are increasingly important to their overall learning experience. It has always been a challenge to offer distance learning students a library experience which is at least equivalent to that of a conventional university. The OU library has been addressing this challenge for the last fifteen years with a significant amount of success.

In the early days the OU library was able to provide access to journal articles as they became available in digital form. But journal articles tend to be more relevant to students in the later stages of their degree, so there was little material available in digital form aimed at first- and second-year undergraduate students. The advent of ebooks, and in particular the growth in academic texts available in ebook form, has allowed us to deliver content online which is more relevant to students studying at levels one and two. Flexibility of access is of paramount importance. Like Emily, the majority of OU students are in full-time employment, and many are also juggling family commitments. Books have to be available to them anytime, anywhere and in the most appropriate formats.

During Emily's studies she will encounter and use ebooks in a number of different contexts. There are two distinct models of providing ebook material at the OU. Some "e-textbooks" will be embedded in the online course materials delivered via the Virtual Learning Environment (VLE) - Moodle, an open source platform that is used at the OU. These are currently procured by the University's production unit, known as Learning \& Teaching Solutions (LTS), who will have arranged payment to clear the rights for either whole textbooks or individual chapters for use by students on this particular course. The university has now adopted a commercial textbook platform to provide easy access and integration with the VLE. Previous versions of Emily's psychology course included a course reader (a collection of rights-cleared journal articles and parts of books) in print. For the latest version of the course Emily is studying, the reader is online and is delivered via the University's structured content markup system that is used for all the core course materials. This means that the content can be delivered in any format and hence on to any desktop or device. "It's so flexible" says Emily "when I went on holiday I downloaded all the course materials and the readings onto my Kindle - I read them on the beach and by the pool, so I didn't get behind at all. I was even able to join in a tutorial while I was away."

The other model is provided by the OU library and is based on providing links to a selection of resources to support the course. These links are managed by the library to ensure that they are "persistent", i.e. they are robust and can cope with changes in supplier, and they are "pushed" into the VLE using RSS feeds. The OU library has recently developed a new back-end system, known as Liblink, that manages this process. When a new course module is developed, a librarian will work alongside the module team to identify and suggest relevant ebooks and other content to be used. Links are likely to be to 
chapters, rather than an entire book. So, for example, there may be an activity written around the chapter.

"Don't you ever have to go and look for books yourself?" asks Carole. "Yes of course - last year, when it was all a bit new to us, we would be given some keywords and told to go into the online library and search for books on a particular subject. This year, now we are at level two, we are expected to search the online library to find books and journals when we have an assignment to do. There are loads to choose from."

Students can search for ebooks via the library search interface, by title or keywords, or they might wish to browse specific collections like PsycBOOKS ${ }^{\circledR}$. However, finding library ebooks is not a straightforward process and provides some challenges for students and libraries. The silos that libraries have been using to manage print and digital resources (library catalogues and knowledge bases) rely on metadata about the individual ebook titles being loaded into the appropriate systems. This can be time-consuming and some ebook collections only have metadata available for the collection rather than all the titles in it.

It is also difficult to provide a true browsing experience for our students that recreates the ability to scan the shelves in a physical library. We try to facilitate this by presenting "Selected resources for your study" lists on the website, and the fairly recent addition of book jacket images makes the experience more "real". The need for anytime, anywhere access has meant that our extensive collection of online reference books is highly valued by students (e.g. Oxford Reference Online, Credo Reference, CRC Netbases). Experience suggests that the online library can encourage a more interdisciplinary approach to learning. Emily, studying psychology, will have easy access to relevant books in medicine, management, education and other related disciplines. In a physical library she may perhaps have been less inclined to venture outside her subject area.

Like many other university libraries, the OU library is experimenting with different models for acquiring ebooks, and we suggest that the experience can have an added significance for us. In our first trial of the Patron or Demand Driven Acquisition (PDA/DDA) model, aimed at Emily and her fellow psychology students, we found that students were choosing a range of general, popular and self-help type books, which may well have been available in a conventional university library but would not have been included in our collections, because our content is generally selected in close liaison with module teams to relate strictly and directly to the curriculum.

\section{The problems and their future solutions}

While the first half of this chapter has hopefully demonstrated the value and importance of ebooks to our distance learners like Emily, and the efforts 
involved behind the scenes, we would not wish to give the impression that all is perfect. As part of our programme of eliciting student feedback, we were able to persuade Emily to join our ebooks focus group. Emily had a number of questions to ask us about her experience of ebooks as a component of her studies. These are the questions she posed:

1. Why do I seem to have to go to so many different places to get my ebooks?

2. Why do so many of the ebooks look completely different and have different rules about what I can do with them, how long I can read them for etc.?

3. Why can't I read them all on my Kindle?

4. Why can't it work like getting books from Amazon or music from iTunes?

We weren't able to provide Emily with satisfactory answers to all her questions. Instead we assured her that these questions would help us to improve services in the future, and to use our influence with publishers.

Let us try to explore the issues behind Emily's questions:

\section{Why do I seem to have to go to so many different places to get my ebooks?}

This is indeed frustrating and there are a number of layers to the answer. First: the e-textbooks which are procured by LTS and embedded into a module, as explained above, will be accessed on a totally different platform from the platforms that are used to access the ebooks provided by the OU library. Why should this be so? In some cases the e-textbook platform is provided by the same company as the library ebook platform and provides the same functionality - why can they not be combined? The answer is that, in the publisher's view, the different business models governing the sale of the content necessitate different rights management (DRM) to be applied to the two types of ebook and therefore access has to be via separate platforms. This view means that publishers often structure their business to separate the sale of ebooks to libraries from institutional procurement or sales to individual students. How can institutions and publishers improve this situation so that the needs of students are better met and they receive a more cohesive service?

Secondly: the OU library currently has no choice but to acquire ebooks from a range of publishers/suppliers all of which have different platforms which look and behave differently. Could we agree to buy them all from one supplier? This is unlikely while the market is so unstable, with publishers developing different platforms, licensing and access models, causing all offers to differ. Our responsibility is to find the best value and the best user experience in every case. 


\section{Why do so many of the ebooks look completely different and have different rules about what I can do with them, how long I can read them for etc.?}

It would appear that publishers and suppliers are experimenting with various business and licensing models. These govern the need for different functionality to be delivered to the end user in different platforms. This makes perfect sense to the supplier but none whatsoever to the user. For Emily it would appear reasonable to expect every book to allow unlimited access and a reasonable amount of downloading and printing but this is far from the case, as the length of time allowed for access can vary significantly. As librarians we can and should continue to put pressure on our suppliers to take the issue of user experience far more seriously and deliver products which meet students' reasonable expectations. We need to be far more proactive in this area.

\section{Why can't I read them all on my Kindle?}

The Open University is now producing its course materials in standard EPUB format which can be rendered to any device. This is regarded as good practice in the digital world and is particularly important for distance learning students who need to access content wherever they are. As a library service we would appear to be failing our students if we are unable to deliver ebooks in the same way. It is hoped that the initial discussions carried out under Jisc's umbrella to establish publisher guidelines for mobile delivery will help to progress this issue. We are selling Emily and her fellow students short in failing to meet expectations in this regard.

\section{Why can't it work like getting books from Amazon or downloading music from iTunes?}

Indeed, these services should and do act as the benchmark for user experience in the digital world, perhaps more because of familiarity and content range than merely usability. Just as libraries have continued to fail to offer a search experience which meets the expectations of Google aficionados, we are unlikely to achieve this in our ability to provide flexible, seamless access to content. Sadly, the academic book industry has seemed to lack the vision and courage to come up with a truly game-changing business model. Can we help to move the process of experimentation forward by articulating a clear vision of what we would like to be offering to our students like Emily? Here are our suggestions for a future vision for ebooks, based on our experience of supporting distance learners.

- Ebooks in the future will provide far more sophisticated functionality than a print book or a single "popular" ebook on a handheld reader. 
- Students will be able to search the content within the books, and access and use parts that are relevant to them, without barriers. This will include the ability to connect content within the ebook with content from other sources.

- Students will be able to access ebooks via a single interface or even a single platform. If there are different platforms, they will be able to move seamlessly between titles regardless of platform.

- Ebooks will meet the highest standards we set for accessibility (to meet the needs of our 12,000 students with disabilities) and they will work effectively on any mobile device.

- The platform(s) will provide a single sign-on authentication that allows students to download and use ebooks of all types wherever they are.

- Search will be integrated across e-textbooks, library ebooks and ebooks that the student has bought, so that the student can transfer between the different "types" of ebook through seamless search and discovery.

- Ebooks purchased by an individual student using their OU student identity would be discounted for them through prearranged deals with publishers. They would be able to annotate, comment on and share these books with their friends.

Although this chapter has focused on the experience of an OU student and the challenges faced by the library on her behalf, we believe that many of the same challenges will be increasingly relevant to the sector as a whole, as online learning moves from margin to mainstream. If librarians, publishers, suppliers and technologists work hard enough together, we may be able to realise the vision articulated above before Emily completes her studies and before all the future Caroles are affected to the same degree. We may have to wait a little longer for the iTunes moment - the true game changer. 